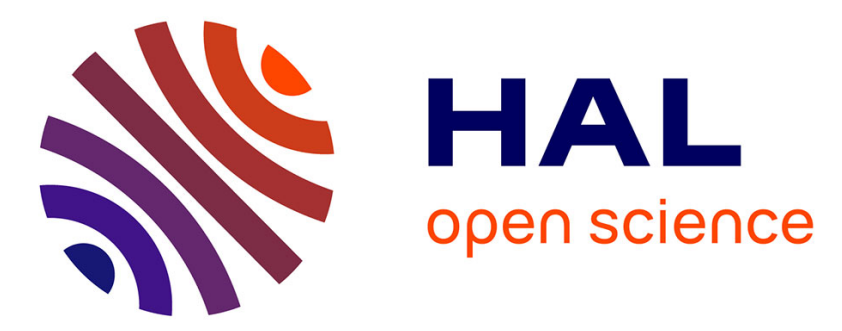

\title{
Conservative surgery in patients with multifocal/multicentric breast cancer
}

Oreste Gentilini, Edoardo Botteri, Nicole Rotmensz, Luciana Lima, Mujgan

Caliskan, Carlos A. Garcia-Etienne, Irina Sosnovskikh, Mattia Intra, Giovanni

Mazzarol, Simona Musmeci, et al.

\section{To cite this version:}

Oreste Gentilini, Edoardo Botteri, Nicole Rotmensz, Luciana Lima, Mujgan Caliskan, et al.. Conservative surgery in patients with multifocal/multicentric breast cancer. Breast Cancer Research and Treatment, 2008, 113 (3), pp.577-583. 10.1007/s10549-008-9959-7 . hal-00478324

\section{HAL Id: hal-00478324 https://hal.science/hal-00478324}

Submitted on 30 Apr 2010

HAL is a multi-disciplinary open access archive for the deposit and dissemination of scientific research documents, whether they are published or not. The documents may come from teaching and research institutions in France or abroad, or from public or private research centers.
L'archive ouverte pluridisciplinaire HAL, est destinée au dépôt et à la diffusion de documents scientifiques de niveau recherche, publiés ou non, émanant des établissements d'enseignement et de recherche français ou étrangers, des laboratoires publics ou privés. 


\title{
Conservative surgery in patients with multifocal/multicentric breast cancer
}

\author{
Oreste Gentilini - Edoardo Botteri - Nicole Rotmensz - Luciana Da Lima • \\ Mujgan Caliskan · Carlos A. Garcia-Etienne · Irina Sosnovskikh · \\ Mattia Intra · Giovanni Mazzarol · Simona Musmeci · Paolo Veronesi · \\ Viviana Galimberti · Alberto Luini · Giuseppe Viale · Aron Goldhirsch • \\ Umberto Veronesi
}

Received: 7 February 2008/ Accepted: 27 February 2008/Published online: 11 March 2008

(C) Springer Science+Business Media, LLC. 2008

\begin{abstract}
Purpose Many physicians recommend mastectomy in case of multifocal (MF) or multicentric (MC) breast cancer due to a theoretical risk of poor local control with less extensive surgery. We retrospectively evaluate outcome of patients with MF/MC cancers who had breast conservation with specific attention on local control and predictive factors of recurrence. Patients and methods Four hundred and seventy six patients with either MF $(n=421)$ or MC $(\mathrm{n}=55)$ breast cancer, underwent breast-conserving surgery between 1997 and 2002 in a single institution. Median follow up was 73 months (range 11-118). Results Median age was 53 years (range 23-86). Invasive lobular carcinoma was found in 88 patients $(18.5 \%)$ and mixed ductal-lobular cancer in $27(5.7 \%)$ patients. Two hundred and sixty-seven patients $(76.7 \%)$ had two identified tumor
\end{abstract}

O. Gentilini $(\bowtie) \cdot$ L. Da Lima · M. Caliskan ·

C. A. Garcia-Etienne - I. Sosnovskikh · M. Intra .

S. Musmeci · P. Veronesi · V. Galimberti · A. Luini ·

G. Viale $\cdot$ U. Veronesi

Division of Breast Surgery, European Institute of Oncology,

Via Ripamonti 435, 20141 Milan, Italy

e-mail: oreste.gentilini@ieo.it

\section{E. Botteri · N. Rotmensz}

Division of Epidemiology and Biostatistics, European Institute of Oncology, Milan, Italy

G. Mazzarol

Division of Pathology and Laboratory Medicine,

European Institute of Oncology, Milan, Italy

P. Veronesi - G. Viale

University of Milan School of Medicine,

European Institute of Oncology, Milan, Italy

A. Goldhirsch

Department of Medicine, European Institute of Oncology,

Milan, Italy foci, 55 patients (15.3\%) had three and 29 patients (8.0\%) had four or more. Two hundred and sixty-one patients $(55.3 \%)$ had nodal involvement. The 5-year cumulative incidence of local relapse was $5.1 \%$. At the multivariate analysis, over-expression of HER2/neu and lack of both estrogen and progesterone receptors (HR: 3.2, 95\% C.I. 1.01-10.0, and HR: 2.7, 95\% C.I. 1.06-7.7, respectively) were associated with a higher ipsilateral breast cancer reappearance rate. Involvement of four or more lymph nodes and lack of estrogen and progesterone receptors (HR: 2.7, $95 \%$ C.I. $1.06-6.7$, and HR: 4.7 , 95\% C.I. $2.1-10.4$, respectively) were associated with poorer overall survival. Conclusions In selected patients with MF/MC breast cancer, wide conservative surgery is not associated with poor local disease control and can be considered whenever acceptable cosmetic results can be achieved.

Keywords Conservative surgery $\cdot$ Breast cancer . Quadrantectomy $\cdot$ Multifocal $\cdot$ Multicentric

\section{Introduction}

With widespread use of mammographic screening and increased accuracy of diagnostic imaging, the surgical treatment of multifocal (MF) and multicentric (MC) breast cancer has come to represent a new challenge for the conservative approach [1]. The presence of multiple foci of cancer within the same breast has traditionally been considered a contraindication for conservative surgery. In fact, many surgeons continue to propose mastectomy for MF/ $\mathrm{MC}$ because earlier series have demonstrated high rates of local recurrence following breast conserving surgery $[2,3]$. Moreover, physicians often recommend mastectomy in order to complete local treatment when unexpected 
multifocality is documented at the final pathologic report, even when surgical margins are disease-free. When two separate tumours are located in different quadrants, breast conservation is not usually considered even in patients with large breasts who might be suitable for a double wide excision. However, the difficulty of endorsing a conservative approach in these patients could be explained by limited available data.

The aim of this study was to retrospectively evaluate the outcome of patients with multiple invasive breast cancer who received conservative surgery with special attention being paid to local control, and to identify predictive factors for recurrence in these patients.

\section{Patients and methods}

Between March 1997 and December 2002, 8100 patients were operated on for invasive breast cancer at the European Institute of Oncology of Milan, Italy and were prospectively entered into our data base. We retrieved 476 patients who underwent conservative surgery for MF or MC breast cancer (at least two different pathologically confirmed invasive foci within the same breast). Diagnosis of multiple invasive breast cancer was performed either clinically by palpation, radiologically or at pathological examination. Multifocality was defined as the presence of different tumours within the same quadrant, and multicentricity as the presence of tumours in different quadrants of the breast, which were managed by a double incision.

All patients' cases were discussed after surgery at a multidisciplinary meeting attended by breast surgery, medical oncology, radiotherapy and pathology specialists. Sixty patients $(12.6 \%)$ received adjuvant chemotherapy alone, 191 patients $(40.1 \%)$ received hormonal therapy alone, and 217 (45.6\%) patients received both chemotherapy and endocrine treatment. Eight patients (1.7\%) did not receive any medical adjuvant treatment.

Four-hundred and fifty-four patients received standard postoperative external whole breast radiotherapy, 13 received intra-operative radiotherapy and nine did not receive any radiation treatment. The median age was 53 years (range 23-86). The median follow up was 73 months (range 11-118).

Two-hundred and seventy eight patients underwent upfront axillary dissection either due to the presence of clinically pathological nodes or because they had been treated before the sentinel node era. Eighty-eight underwent sentinel lymph node biopsy (SLNB) and axillary dissection because of the presence of metastases in the sentinel node, 106 received SLNB alone, and four did not have any axillary staging.
All those patients who were not seen in the last 6 months were contacted by telephone in order to update the follow up. No patients were lost to follow up.

\section{Pathology}

The distinction between the tumors was assessed both grossly, recording the distance between the foci and microscopically, routinely sampling the interposed tissue between the neoplastic foci. Multifocality and multicentricity were prospectively diagnosed on the pathology report only if the interposed tissue was free of neoplasia, both in situ or infiltrating.

HER-2/neu over-expression was investigated immunohistochemically, using a specific polyclonal antiserum (Dako A/S, Carpinteria, CA). The staining results were recorded in a four-tier scale, from 0 to $3+$, according to the percentage of immunoreactive cells, and to the intensity and completeness of membrane staining as recommendend by the Food and Drug Administration, USA [4]. Only an intense and complete membrane staining of the tumour cells $(3+)$ was taken as evidence of Her2/neu over-expression.

Patients with distant metastases, bilateral cancer, clinical or pathological $\mathrm{T} 4$ or those who received primary medical treatment were excluded from the analysis. Table 1 summarizes the patients' and tumours' characteristics. The reported tumor size represents the largest tumor focus. Ten patients had focally positive margins at the final pathologic report and, after careful discussion of the available options, were not submitted to re-excision according to patient' preference.

\section{Statistical considerations}

Primary endpoints were cumulative incidence of local events, cumulative incidence of first events and cumulative mortality. Recurrences within the same breast, with or without involvement of regional nodes, were considered as local events. First events were any type of recurrence, second primary cancer, contralateral breast cancer recurrence or death, whichever occurred first. If patients had simultaneous local and distant recurrence they were considered as having a distant recurrence in the analysis. Cumulative mortality was calculated as the cumulative incidence of deaths from any cause.

Crude cumulative incidence of local events was computed in a competing risk framework as described by Marubini and Valsecchi [5], and compared across different subgroups by means of the Gray test [6]. The Log-rank test was used to assess survival differences between groups for cumulative incidence of first events and cumulative mortality. Multivariate Cox proportional hazards regression 
Table 1 Patients' characteristics and stratification for multifocal/multicentric tumours

\begin{tabular}{|c|c|c|c|c|c|}
\hline Variable & Classification & Total No. $(\%)$ & Multifocal No. (\%) & Multicentric No. (\%) & Chi-square $P$-value \\
\hline All patients & & 476 & $421(88.4)$ & 55 (11.6) & \\
\hline \multirow[t]{4}{*}{ Age } & $<35$ years & $25(5.3)$ & $23(5.5)$ & $2(3.6)$ & 0.492 \\
\hline & $35-49$ years & $178(37.4)$ & $159(37.8)$ & 19 (34.6) & \\
\hline & $50-64$ years & $200(42.0)$ & $172(40.9)$ & $28(50.9)$ & \\
\hline & $\geq 65$ years & $73(15.3)$ & $67(15.9)$ & $6(10.9)$ & \\
\hline \multirow[t]{2}{*}{ Menopause } & Pre & $193(40.6)$ & $171(40.6)$ & $22(40.0)$ & 0.930 \\
\hline & Peri/post & $283(59.4)$ & $250(59.4)$ & $33(60.0)$ & \\
\hline \multirow[t]{3}{*}{ Number of foci ${ }^{\mathrm{a}}$} & 2 & $276(76.7)$ & $246(79.4)$ & $30(60.0)$ & 0.011 \\
\hline & 3 & $55(15.3)$ & $42(13.6)$ & $13(26.0)$ & \\
\hline & $\geq 4$ & $29(8.0)$ & $22(7.1)$ & $7(14.0)$ & \\
\hline \multirow[t]{3}{*}{ pT } & pT1a-pT1b & $84(17.7)$ & $77(18.3)$ & $7(12.7)$ & 0.529 \\
\hline & pT1c & $257(54.0)$ & $227(53.9)$ & $30(54.6)$ & \\
\hline & pT2-pT3 & 135 (28.4) & $117(27.8)$ & $18(32.7)$ & \\
\hline \multirow[t]{2}{*}{ Extensive in situ component } & Absent & $297(62.4)$ & $262(62.2)$ & 35 (63.6) & 0.840 \\
\hline & Present & 179 (37.6) & $159(37.8)$ & $20(36.4)$ & \\
\hline \multirow[t]{3}{*}{ Margins } & Negative $(>1 \mathrm{~mm})$ & $421(88.5)$ & $372(88.4)$ & $49(89.1)$ & 0.983 \\
\hline & Close $(\leq 1 \mathrm{~mm})$ & $45(9.4)$ & $40(9.5)$ & $5(9.1)$ & \\
\hline & Positive & $10(2.1)$ & $9(2.1)$ & $1(1.8)$ & \\
\hline \multirow[t]{3}{*}{ Number of positive lymph nodes ${ }^{a}$} & 0 & $211(44.7)$ & $186(44.5)$ & $25(46.3)$ & 0.795 \\
\hline & $1-3$ & $167(35.4)$ & $150(35.9)$ & 17 (31.5) & \\
\hline & $\geq 4$ & $94(19.9)$ & $82(19.6)$ & $12(22.2)$ & \\
\hline \multirow[t]{4}{*}{ Histotype } & Ductal & $333(70.0)$ & $294(69.8)$ & $39(70.9)$ & $0.928^{\mathrm{b}}$ \\
\hline & Lobular & $88(18.5)$ & $78(18.5)$ & $10(18.2)$ & \\
\hline & Mixed Duct.-Lob. & $27(5.7)$ & $22(5.2)$ & $5(9.1)$ & \\
\hline & Other & $28(5.9)$ & $27(6.4)$ & $1(1.8)$ & \\
\hline \multirow[t]{2}{*}{ Estrogen receptors } & Positive & 417 (87.6) & $369(87.6)$ & $48(87.3)$ & 0.937 \\
\hline & Negative & $59(12.4)$ & $52(12.4)$ & $7(12.7)$ & \\
\hline \multirow[t]{2}{*}{ Progesterone receptors } & Positive & $372(78.2)$ & $329(78.2)$ & $43(78.2)$ & 0.995 \\
\hline & Negative & $104(21.8)$ & $92(21.8)$ & $12(21.8)$ & \\
\hline \multirow[t]{3}{*}{ Grading $^{\mathrm{a}}$} & G1 & $65(14.1)$ & $59(14.5)$ & $6(11.1)$ & 0.777 \\
\hline & G2 & $250(54.1)$ & $219(53.7)$ & $31(57.4)$ & \\
\hline & G3 & $147(31.8)$ & $130(31.9)$ & 17 (31.5) & \\
\hline \multirow[t]{2}{*}{ HER2/neu ${ }^{a}$} & Over-expressed & $40(13.3)$ & $32(12.5)$ & $8(18.6)$ & 0.272 \\
\hline & Not over-expressed & $260(86.7)$ & $225(87.5)$ & 35 (81.4) & \\
\hline \multirow[t]{2}{*}{$\mathrm{Ki}-67^{\mathrm{a}}$} & $<20 \%$ & $235(49.7)$ & $209(50.0)$ & $26(47.3)$ & 0.704 \\
\hline & $\geq 20 \%$ & $238(50.3)$ & $209(50.0)$ & $29(52.7)$ & \\
\hline \multirow[t]{3}{*}{ Vascular invasion } & Absent & $327(68.7)$ & $292(69.4)$ & $35(63.6)$ & 0.584 \\
\hline & Present & $81(17.0)$ & $69(16.4)$ & $12(21.8)$ & \\
\hline & Extensive & $68(14.3)$ & $60(14.3)$ & $8(14.3)$ & \\
\hline
\end{tabular}

a Information is not available for all the patients

b Lobular vs. ductal. The reported tumor size represents the largest tumor focus

Bolded entries indicate statistical significance (i.e. $P$-value $<0.05$ )

models were used to identify the prognostic independent clinico-pathological features associated with survival. For local events, Cox Proportional Hazard model was computed in a competing risk framework [7]. All analyses were performed with the SAS software (SAS Institute, Cary, NC) and the R software (The R Development Core Team 2004; Free Software Foundation, Boston, MA). All tests were two-sided. 
Table 2 Description of events

\begin{tabular}{lr}
\hline Description of events & No. $(\%)$ \\
\hline First event & \\
Local $^{\mathrm{a}}$ & $24(5.0)$ \\
Loco-regional $^{\mathrm{a}}$ & $2(0.4)$ \\
Regional & $7(1.5)$ \\
Distant & $51(10.7)$ \\
Local and distant & $1(0.2)$ \\
Contralateral breast tumor & $6(1.3)$ \\
Other primary tumor & $11(2.3)$ \\
Death as first event (any cause) & $9(1.9)$ \\
Death (any cause) & $36(7.6)$ \\
\hline
\end{tabular}

${ }^{a}$ Considered as local events in the following analyses

\section{Results}

Median age was 53 years (range 23-86). Table 1 shows patients' and tumor characteristics with stratification for multifocal (MF) and multicentric (MC) tumours. Four hundred and twenty-one patients $(88.4 \%)$ had $\mathrm{MF}$ and 55 (11.6\%) had MC disease. The only difference between patients with MF and MC tumours was that the number of foci was significantly higher in patients with MC disease. Invasive lobular carcinoma was diagnosed in 88 patients (18.5\%) and invasive mixed ductal-lobular cancer in 27 $(5.7 \%)$. Two hundred and sixty-seven patients $(76.7 \%)$ had 2, 55 patients $(15.3 \%)$ had three and 29 patients $(8.0 \%)$ had 4 or more tumor foci. Two hundred and sixty-one patients (55.3\%) had nodal involvement.

Table 2 describes the events. Briefly, 24 patients $(5.0 \%)$ developed ipsilateral breast recurrence, $2(0.4 \%)$ had locoregional recurrence, and $51(10.7 \%)$ had distant metastases as first event.

Figures 1 and 2 represent cumulative incidence of local recurrence $(5.1 \%$ at 5 years) and mortality $(6.2 \%$ at 5 years), respectively.

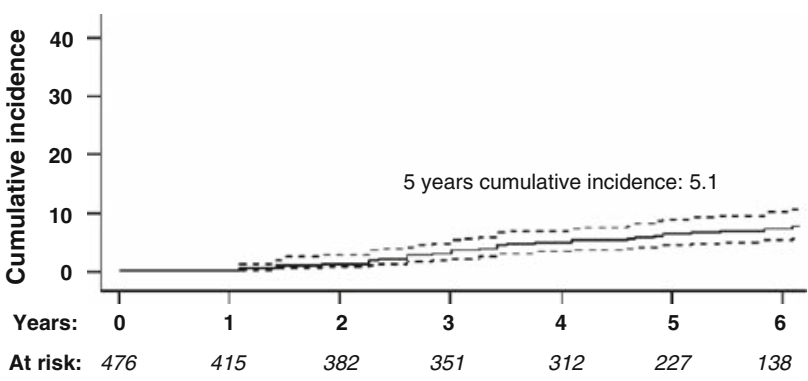

Events: local events. Dotted lines: 95\% confidence interval bands. Cumulative incidence and $95 \%$ confidence interval bands were computed in a competing risk framework.

Fig. 1 Cumulative incidence of local events

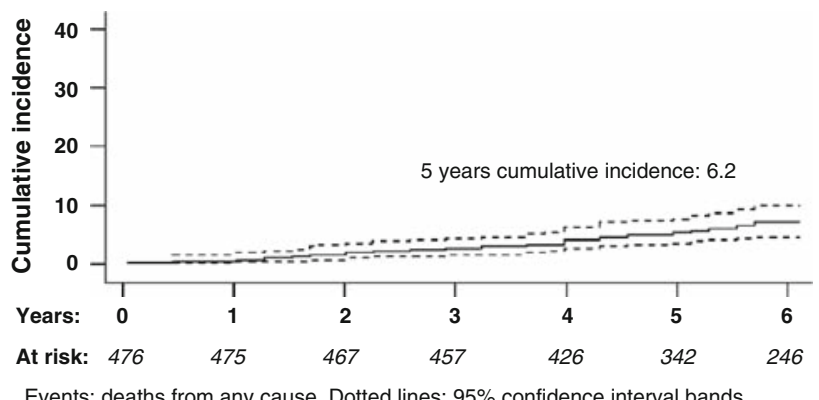

Fig. 2 Cumulative mortality

Factors related to local and distant relapses, and to overall survival at the univariate and multivariate analyses are listed in Tables 3 and 4, respectively.

At the multivariate analysis, over-expression of HER2/ neu and lack of both estrogen and progesterone receptors (HR: 3.2 , 95\% C.I. $1.01-10.0$, and HR: 2.7 , 95\% C.I. $1.06-$ 7.7 , respectively) were associated with higher ipsilateral breast cancer reappearance rate. Involvement of 4 or more lymph nodes and lack of estrogen and progesterone receptors (HR: 2.7, 95\% C.I. 1.06-6.7, and HR: 4.7, 95\% C.I. 2.1-10.4, respectively) were associated with poorer overall survival.

\section{Discussion}

To our knowledge, few papers [2, 3, 8-13] have been published concerning conservative surgery in patients with $\mathrm{MF} / \mathrm{MC}$, and all have dealt with a limited number of patients. Former series reported a high risk of local recurrence in patients treated with conservative surgery. In fact, Kurtz et al. [2] in their experience with 61 patients with two or more macroscopic tumor nodules, concluded that patients with macroscopically multiple invasive breast cancer were at a higher risk of local failure if tumors were clinically or radiologically apparent $(36 \%$ rate of local recurrence). Wilson and colleagues [3] reported that the local recurrence rate was greater in patients with synchronous ipsilateral breast cancer as compared to patients with single lesions (72-month actuarial breast recurrence rate of $25 \%$ and $12 \%$, respectively). More recently, Cho et al. [11] reported that in selected cases the combination of conservative surgery and radiation therapy resulted in acceptable local-regional control, based on their experience with 15 patients affected by multiple ipsilateral invasive breast cancer. Kaplan et al. [12], after evaluating their experience with 36 patients, concluded that breast conservation is an effective treatment for patients with synchronous ipsilateral breast carcinoma. Okumura and colleagues [13] compared 34 patients with multiple invasive breast cancer to 594 patients with unifocal disease and 
Table 3 Univariate analysis of prognostic factors

\begin{tabular}{|c|c|c|c|c|c|c|c|}
\hline \multirow[t]{2}{*}{ Variable } & \multirow[t]{2}{*}{ Classification } & \multicolumn{2}{|l|}{ Local events } & \multicolumn{2}{|l|}{ All first events } & \multicolumn{2}{|l|}{ Deaths } \\
\hline & & $\begin{array}{l}\text { Events ( } 5 \text { years } \\
\text { Cum Inc) }\end{array}$ & $P$-value & $\begin{array}{l}\text { Events ( } 5 \text { years } \\
\text { Cum Inc) }\end{array}$ & $P$-value & $\begin{array}{l}\text { Events ( } 5 \text { years } \\
\text { Cum Inc) }\end{array}$ & $P$-value \\
\hline All patients & & $26(5.1)$ & & $111(23.5)$ & & $36(6.2)$ & \\
\hline \multirow[t]{4}{*}{ Age } & $<35$ years & $2(8.5)$ & 0.130 & $8(25.9)$ & 0.131 & $2(8.0)$ & 0.008 \\
\hline & $35-49$ years & $11(6.0)$ & & $38(22.6)$ & & $6(3.6)$ & \\
\hline & 50-64 years & $6(2.4)$ & & $42(19.5)$ & & $17(6.4)$ & \\
\hline & $\geq 65$ years & $7(9.7)$ & & $23(35.4)$ & & $11(11.2)$ & \\
\hline \multirow[t]{2}{*}{ Multifocal/multicentric } & Multifocal & $23(4.9)$ & 0.829 & $97(23.2)$ & 0.393 & $31(6.0)$ & 0.515 \\
\hline & Multicentric & $3(8.0)$ & & $14(26.2)$ & & $5(7.6)$ & \\
\hline \multirow[t]{2}{*}{ Number of foci ${ }^{a}$} & 2 & $7(2.4)$ & 0.192 & $56(22.5)$ & 0.832 & $17(5.0)$ & 0.802 \\
\hline & $3+$ & $5(5.7)$ & & $19(19.8)$ & & $6(5.4)$ & \\
\hline \multirow[t]{3}{*}{ pT } & pT1a-pT1b & $7(10.6)$ & 0.347 & $15(22.5)$ & 0.014 & $5(4.9)$ & 0.210 \\
\hline & pT1c & $12(4.9)$ & & $50(20.6)$ & & $16(5.8)$ & \\
\hline & pT2-pT3 & $7(5.1)$ & & $46(29.1)$ & & $15(7.7)$ & \\
\hline \multirow[t]{2}{*}{ Extensive in situ component } & Absent & $14(5.0)$ & 0.597 & $69(25.1)$ & 0.584 & $26(7.1)$ & 0.101 \\
\hline & Present & $12(6.0)$ & & $42(20.9)$ & & $10(4.7)$ & \\
\hline \multirow[t]{2}{*}{ Margins } & Negative/close & $25(5.5)$ & 0.313 & $108(23.1)$ & 0.286 & $35(6.0)$ & 0.793 \\
\hline & Positive & $1(25.0)$ & & $3(50.0)$ & & $1(12.5)$ & \\
\hline \multirow[t]{3}{*}{ Number of positive lymphnodes ${ }^{a}$} & 0 & $8(3.7)$ & $0.308^{\mathrm{b}}$ & $26(12.5)$ & $<\mathbf{0 . 0 0 1}^{\mathrm{b}}$ & $9(3.4)$ & $<\mathbf{0 . 0 0 1}{ }^{\mathrm{b}}$ \\
\hline & $1-3$ & $12(5.6)$ & & $41(23.8)$ & & $13(6.4)$ & \\
\hline & $\geq 4$ & $5(6.3)$ & & $43(45.0)$ & & $13(11.2)$ & \\
\hline \multirow[t]{2}{*}{ Histotype } & Ductal & $20(6.1)$ & 0.638 & $87(26.9)$ & 0.229 & $29(8.0)$ & 0.805 \\
\hline & Lobular & $4(4.4)$ & & 17 (17.6) & & $7(3.4)$ & \\
\hline \multirow[t]{2}{*}{ Estrogen receptors } & Positive & $18(4.1)$ & 0.003 & $84(19.8)$ & $<\mathbf{0 . 0 0 1}$ & $22(3.6)$ & $<\mathbf{0 . 0 0 1}$ \\
\hline & Negative & $8(16.1)$ & & $27(48.5)$ & & $14(24.2)$ & \\
\hline \multirow[t]{2}{*}{ Progesterone receptors } & Positive & $13(2.8)$ & $<\mathbf{0 . 0 0 1}$ & $71(17.7)$ & $<\mathbf{0 . 0 0 1}$ & $17(3.1)$ & $<\mathbf{0 . 0 0 1}$ \\
\hline & Negative & $13(15.6)$ & & $40(43.6)$ & & $19(16.9)$ & \\
\hline \multirow[t]{3}{*}{ Grading $^{\mathrm{a}}$} & G1 & $0(0.0)$ & $0.046^{c}$ & $6(9.0)$ & $<\mathbf{0 . 0 0 1}^{\mathrm{c}}$ & $2(3.1)$ & $<\mathbf{0 . 0 0 1}^{\mathrm{c}}$ \\
\hline & $\mathrm{G} 2$ & $13(5.3)$ & & $42(16.0)$ & & $11(2.7)$ & \\
\hline & G3 & $10(6.4)$ & & $59(40.6)$ & & $22(13.4)$ & \\
\hline \multirow[t]{2}{*}{ Her $2 /$ neu $^{a}$} & Overexpressed & $7(19.8)$ & $<0.001$ & $23(56.9)$ & $<\mathbf{0 . 0 0 1}$ & $10(26.9)$ & $<\mathbf{0 . 0 0 1}$ \\
\hline & Not overexpr. & $9(4.0)$ & & $49(20.9)$ & & $16(4.4)$ & \\
\hline \multirow[t]{2}{*}{$\mathrm{Ki}-67^{\mathrm{a}}$} & $<20 \%$ & $8(3.5)$ & 0.036 & $34(14.4)$ & $<\mathbf{0 . 0 0 1}$ & $11(2.2)$ & 0.013 \\
\hline & $\geq 20 \%$ & $18(7.9)$ & & $77(32.4)$ & & $25(10.2)$ & \\
\hline \multirow[t]{3}{*}{ Vascular invasion } & Absent & $14(3.8)$ & $0.135^{\mathrm{d}}$ & $57(17.3)$ & $<\mathbf{0 . 0 0 1}^{\mathrm{d}}$ & $19(4.1)$ & $\mathbf{0 . 0 3 3}^{\mathrm{d}}$ \\
\hline & Present & $5(8.1)$ & & $23(32.5)$ & & $8(9.5)$ & \\
\hline & Extensive & $7(8.3)$ & & $31(40.3)$ & & $9(12.1)$ & \\
\hline
\end{tabular}

Five-year cumulative incidences for local events were computed in a competing risk framework and compared by the Gray test. Five-year cumulative incidences for first events and deaths were compared by the log-rank test. Bolded entries indicate statistical significance (i.e. $P$-value $<0.05)$

${ }^{a}$ Information is not available for all patients

b Positive vs. negative

c G2-G3 vs. G1

${ }^{\mathrm{d}}$ Present/extensive vs. absent

did not find any difference in terms of local control, disease-free survival or cosmetic result.

Our attitude is strongly in favour of breast conservation, and we elect this surgical approach as the treatment of choice, even for patients with multiple invasive cancer as long as it is technically and cosmetically feasible. Here, we re-evaluate the largest series of patients with pathologically confirmed multiple foci of breast cancer and treated with 
Table 4 Multivariate analysis

\begin{tabular}{|c|c|c|c|c|}
\hline & Comparisons & $\begin{array}{l}\text { Local events } \\
\text { HR (95\% C.I.) }\end{array}$ & $\begin{array}{l}\text { All first events } \\
\text { HR (95\% C.I.) }\end{array}$ & $\begin{array}{l}\text { Deaths } \\
\text { HR (95\% C.I.) }\end{array}$ \\
\hline $\mathrm{pT}$ & pT2/3 vs. pT1 & - & $1.17(0.78 ; 1.75)$ & - \\
\hline \multirow[t]{2}{*}{ Number of positive lymphnodes } & $1-3$ vs. 0 & - & $1.86(1.12 ; 3.08)$ & $1.68(0.70 ; 4.00)$ \\
\hline & $4+$ vs. 0 & - & $2.73(1.58 ; 4.75)$ & $2.65(1.06 ; 6.66)$ \\
\hline Er/Pgr receptors & Both absent vs. at least one positive & $2.76(1.06 ; 7.68)$ & $2.40(1.43 ; 4.05)$ & $4.68(2.10 ; 10.4)$ \\
\hline Her2/neu & Overexpressed vs. not overexpressed & $3.18(1.01 ; 10.0)$ & $1.64(0.92 ; 2.93)$ & $1.82(0.71 ; 4.67)$ \\
\hline $\mathrm{Ki}-67$ & $\geq 20$ vs. $<20$ & $1.45(0.57 ; 3.68)$ & $1.45(0.92 ; 2.27)$ & $1.31(0.59 ; 2.92)$ \\
\hline Vascular invasion & Present/extensive vs. absent & - & $1.50(0.98 ; 2.29)$ & $1.86(0.89 ; 3.88)$ \\
\hline
\end{tabular}

Hazard ratios and confidence intervals were calculated using the Cox Proportional Hazard model. For local events the Cox Proportional Hazard model was computed in a competing risk framework. The model for mortality was adjusted for age considered as a continuous variable. Bolded entries indicate statistical significance (i.e. $P$-value $<0.05$ )

breast conservation. Our cohort comprises patients with multiple palpable tumours located within the same quadrant or in different quadrants, or patients with an unexpected MF invasive disease found at the final pathological report. Multifocalilty and multicentricity in breast cancer are historically defined as the presence of two or more tumor foci within a single quadrant of the breast or within different quadrants of the same breast, respectively [14]. The only significant difference between patients with MF and MC tumours was the number of foci, which was higher in patients with MC disease. In our opinion, these definitions help to simply illustrate two different scenarios of multiple invasive breast cancer. As two separate tumors within the same quadrant could in fact be more distant from each other than two tumors located in different quadrants, it is important to point out that strict definitions run the risk of falling into discussions which are merely semantic. The distance between tumors should also be regarded with caution, as overall proportion with breast size should be also taken into account.

It is interesting to note that despite the high rate of node metastases (55\% of the patients), as expected in MF/MC breast cancer [15, 16], distant metastases occurred in only $10.7 \%$ of the patients. One might speculate that the high rate of endocrine-responsive tumours in this series $(87.6 \%)$, which is probably related to the high prevalence of invasive lobular carcinomas, might lead to a better outcome following adequate adjuvant treatment at least during the first 5 years. Furthermore, patients with lobular or ductal carcinoma had a similar outcome in terms of local recurrence ( 4.4 and $6.1 \%$, respectively). This confirms that, despite the common multifocality and bilaterality of invasive lobular carcinoma, its occurrence does not by itself preclude breast conservation, as long as it is adequately excised.

The main finding of our study is that the 5 years cumulative incidence of local relapse was $5.1 \%$, which is in our opinion quite acceptable and similar to that reported in patients with unifocal disease $[17,18]$. Therefore, these data, derived from a large series of patients, emphasize that breast conserving surgery is safe for patients with $\mathrm{MF} / \mathrm{MC}$ breast cancer, as it provides acceptable local control when the disease is adequately excised. Furthermore, breast conservation achieved a good outcome even in patients with MC disease who were treated with separate wide local excisions ( $8 \% 5$ years cumulative incidence of local relapse).

The multivariate analysis which showed that over-expression of HER2/neu and lack of estrogen and progesterone receptors worsened local disease free survival. Due to the availability of an effective therapy against cells over-expressing HER2/neu it is likely that outcome will be improved with the adjuvant administration of trastuzumab [19, 20].

This is a retrospective analysis and therefore some limitations have to be underlined. First, we were not able to collect reliable data on clinical and radiological presentation. It would be interesting to have this information in order to better characterize the patient cohort. Obviously, all patients with multicentric cancer had preoperative diagnosis since they underwent double incision but for the majority of the population we cannot say how many patients had either clinically palpable lumps or radiologically detected tumours or incidental finding at surgery or at pathologic evaluation. Secondly, this is a selected population of patients. In fact, all these women were considered suitable for breast conservation from both the oncologic and cosmetic point of view after careful discussion.

Despite the above mentioned limitations and critiques which might be raised, we think that these data are of important clinical interest since only a few papers with a limited number of patients have been reported so far on this topic. In specialized centers with high patient volume conservative surgery is usually performed in presence of multifocal cancer, but many surgeons or medical oncologists acting in community hospitals continue to recommend mastectomy for the presence of multifocality itself.

As stated earlier, patients were selected for the expected acceptable cosmetic outcome as well. In most cases of 
multicentric cancer women had large breasts with tumors far each other and located at the periphery of the breast. In this clinical scenario it is not hard to imagine that satisfactory outcome could be achieved.

We believe that the data collected within this study are relevant to the discussion with motivated patients in order to decide upon the type of surgery to be conducted. Given the low rate of local recurrence, in selected patients breast conservation can be considered for patients with MF/MC breast cancer, whenever adequate surgery and acceptable cosmetic results can be achieved.

\section{References}

1. Coombs NJ, Boyorges J (2005) Multifocal and multicentric breast cancer: does each focus matter? J Clinl Oncol 23:7497-7502

2. Kurtz JM, Jacquemier J, Amatric R et al (1990) Breast conserving therapy for macroscopically multiple cancer. Ann Surg 212:38-44

3. Wilson LD, Beinfield M, McKhan CF et al (1993) Conservative surgery and radiation in treatment of synchronous ipsilateral breast cancers. Cancer 72:137-142

4. Jacobs TW, Gown AM, Yaziji H (1999) Specificity of Herceptest in determining HER2/neu status of breast cancer using the United States Food and Drug Administration-approved scoring system. J Clin Oncol 17:1983-1987

5. Marubini E, Valsecchi MG (1995) Analysing survival data from clinical trials and observational studies. Wiley, Chichester, p 331

6. Gray RJ (1988) A class of k-sample tests for comparing the cumulative incidence of a competing risk. Ann Stat 16:11411154

7. Putter H, Fiocco M, Geskus RB (2007) Tutorial in biostatistics: competing risks and multi-state models. Stat Med 26:2389-2430

8. Nos C, Bourgeois D, Darles C, Asselain B, Campana F, Zafrani B, Durand JC, Clough K (1999) Conservative treatment of multifocal breast cancer: a comparative study. Bull Cancer 86:84-88
9. Leopold KA, Recht A, Schnitt S et al (1989) Results of conservative surgery and radiation therapy for multiple synchronous cancers of one breast. Int J Radiat Oncol Biol Phys 16:11-16

10. Fowble B, Yeh IT, Schultz DJ et al (1993) The role of mastectomy in patients with stage I-II breast cancer presenting with gross multifocal or multicentric disease or diffuse microcalcifications. Int J Radiat Oncol Biol Phys 27:567-573

11. Cho LC, Senzer N, Peters GN (2002) Conservative surgery and radiation therapy for macroscopically multiple ipsilateral invasive breast cancers. Am J Surg 183:650-654

12. Kaplan J, Giron G, Tartter PI, Bleiweiss IJ, Estabrook A, Smith SR (2003) Breast conservation in patients with multiple ipsilateral synchronous cancers. J Am Coll Surg 197:726-729

13. Okumura S, Mitsomuri M, Yamauchi C et al (2004) Feasibility of breast-conserving therapy for macroscopically multiple ipsilateral breast cancer. Int J Radiat Oncol Biol Phys 59:146-151

14. Lagios MD, Westdahl PR, Rose MR (1981) The concept and implications of multicentricity in breast carcinoma. Pathol Annu $16: 83-102$

15. Andea AA, Wallis T, Newman LA, Bouwman D, Dey J, Visscher D (2002) Pathologic Analysis of tumor size and lymph node status in multifocal/multicentric breast carcinoma. Cancer 94:1383-1390

16. Gentilini O, Trifiro ' G, Soteldo J et al (2006) Sentinel lymph node biopsy in multicentric breast cancer. The experience of the European Institute of Oncology. Eur J Surg Oncol 32:507-510

17. Veronesi U, Cascinelli N, Mariani L et al (2003) Twenty years follow up of randomized study comparing breast conserving surgery with radical mastectomy for early breast cancer. N Engl J Med 347:1227-1232

18. Fisher B, Anderson S, Bryant J et al (2002) Twenty year follow up of a randomised study comparing total mastectomy, lumpectomy, and lumpectomy plus irradiation for the treatment of invasive breast cancer. N Engl J Med 347:1233-1241

19. Piccart-Gebhart MJ, Procter M, Leyland-Jones B et al (2005) Trastuzumab after adjuvant chemotherapy for HER2- positive breast cancer. N Engl J Med 353:1679-1672

20. Romond EH, Perez EA, Bryant J et al (2005) Trastuzumab plus adjuvant chemotherapy for operable HER2-positive breast cancer. N Engl J Med 353:1673-1684 